\title{
Kardiyovasküler Cerrahide Kullanıma Yönelik Ag-Gümüş İyon İmplantasyonlu PoliTetraFloroEtilen (PTFE) Malzemelerin Yüzey Özellikleri ve Antibakteriyel Aktivitesi
}

\author{
Senem Öngel ${ }^{1}$, Emel Sokullu $^{2^{*}}$, Ahmet Öztarhan ${ }^{1}$ \\ 1 Ege Üniversitesi, Biyomühendislik Bölümü, Bornova İzmir \\ 2 İzmir Katip Çelebi Üniversitesi, Mühendislik Bilimleri, Biyomühendislik B. Harmandalı Çiğli İzmir \\ emelsu@gmail.com \\ *Iletişimden sorumlu yazar/Corresponding author \\ Geliş/Recieved: 1 Aralık (December) 2016 \\ Kabul/Accepted: 28 Nisan (April) 2017 \\ DOI: $10.18466 /$ cbayarfbe.319926
}

\begin{abstract}
Özet
Bu çalışmada yapay damar malzemesi olarak kullanılan ePTFE numunelerine metal+gaz hibrid iyon implantasyonu yapılarak antibakteriyel ve süperhidrofob özellikler kazandırılmıştır. Çalışmanın amac1, kalp ve damar cerrahisinde kullanılan genişletilmiş politetrafloroetilen (ePTFE) yapay damarlarda oluşan sorunların giderilmesi amacıyla iyon implantasyonu yapılan ePTFE numunelere kazandırılan bazı özellikleri incelemektir. Çalışma, ePTFE numune yüzeylerinin $\mathrm{Ag}^{+}$iyon implantasyonu ile modifiye edilmesi, modifiye edilmiş bu malzemelere antibakteriyel test yapilarak bakteri azalmasının incelenmesi, modifiye edilmiş malzemelerin temas açılarının ölçülmesi ve modifiye edilmiş ePTFE yüzeylerin AFM ile yüzey pürüzlülüklerinin ölçülmesini içermektedir. Sonuç olarak, $\mathrm{Ag}^{+}$ile gerçekleştirilen implantasyonlarda, temas açlları ölçüldüğünde malzeme süperhidrofob özellik sağlanmıştır. Antibakteriyel test sonuçlarında ise, S.aureus bakterisiyle yapılan testlerde S.aureus bakterisinin azaldığı görülmüştür. İyon implantasyonu yapılmış numunelerde yüzey pürüzlülük değerlerinin belirgin olarak azaldığı görülmüştür.
\end{abstract}

Anahtar Kelimeler - İyon implantasyonu, MEVVA, Ag, antibakteriyel, ePTFE

\section{Surface Characteristics and Antibacterial Activity of Ag-Silver Ion Implanted PolyThetraFluoroEthylene (PTFE) as a Cardiovascular Surgery Material}

\begin{abstract}
In this work, ePTFE samples, which have been used as artificial vein materials, were metal+gas hybrid ion implanted to gain antibacterial and superhydrophobe properties. The purpose of this study was to study some properties of ion implanted expanded-polytetrafluoroethylene samples, which are used in cardiovascular surgery, with the purpose of eliminating the problems. The work consists of surface modification of ePTFE samples by $\mathrm{Ag}^{+}$ion implantation, study of the antibacterial properties of these ion implanted samples by antibacterial tests, contact angle measurements of ion implanted samples and measurements of surface roughness of ion implanted ePTFE surfaces by AFM. Experimental results showed that superhydrophobicity were obtained by ion implantation. Antibacterial tests showed that S.aureus bacteria were decreased after ion implantation. It was observed clearly that the roughness of ion implanted ePTFE surfaces decreased.
\end{abstract}

Keywords - Ion implantation, MEVVA, Ag, antibacterial, ePTFE

\section{Giriş}

Hasta sayısındaki artış, teşhis ve tedavideki ilerleme- 
lere bağlı olarak kardiyovasküler hastalıkların önemi günden güne artmaktadır. Bazı cerrahi operasyonlarda arterlerin (atardamarlar) değişmesi gereken durumlarla karşılaşılabilir. Hasarlı ve hastalıklı damarların değiştirilmesinde organik damar protezlerin yerini alan yapay malzemeler kullanılmaktadır. Gerçek arterlerle aynı fiziksel ve kimyasal özelliklere sahip vasküler greflerin geliştirilmesi tıbbi alanda büyük bir gelişme sağlamaktadır[1]. Sentetik vasküler protezlerin dizaynı ve üretimi son yıllarda cerrahide önemli bir yer tutmaktadır. Yeterli organik protez (otogreft) bulunamadığı durumlarda genel bypass yöntemleri yerine yapay damarlar kullanılmaktadır. Son yıllarda vasküler greft (yapay damar) üretimi artış göstermiştir[2]. Kardiyovasküler cerrahide kullanilan yapay malzemeler ve damar protezlerde daha önce kullanılmış materyaller Vinyon N, Orlon, Naylon 6, Ivalon sponj, Dacron ve Teflon'dur. Ancak günümüzde poliester (PET) ve politetrafloroetilen (PTFE) materyaller tercih edilmektedir[2].

Yapay malzemeler (venöz ve arteryel otogreftler), hastalıklı ve hasarlı kan damarlarının değiştirilmesinde seçilecek en ideal materyallerdir[2]. Cerrahi operasyonlarda anevrizma olan genişlemiş damar bölümü açılıp pihtılar temizlendikten sonra sağlam damar bölümleri arasına yapay damar yerleştirilir[2]. ePTFE yapay greftler, $6 \mathrm{~mm}$ 'den küçük çaplarda tercih edilen damarlardır. Sentetik greftlerin trombojenite riski yükselmektedir. Yani akut trombüs formasyonu oluşma sıklığı artmaktadır. İntimal (neointimal) hiperplaziye yol açmamalıdır. Hiperplazi, greftin distal ve proksimal ucunda bulunan vasküler düz kas hücreleridir. Komplians yoktur[3].

Politetrafloroetilen (PTFE), TEFLON® ticari adıyla bilinen bir sentetik materyaldir. Bilinen en az reaktif ve en iyi inert materyaldir. Teflon greft olarak ilk kez 1967'de Jr. Sawyer tarafından kullanılmıştır[2]. Genişletilmiş PTFE (ePTFE), ticari adıyla GORO-TEX® teflonun isitılıp gerilerek zorla genişletildiği bir florokarbon polimeridir. PTFE (genişletilmiş politetrafloroetilen) 1969 ' da Robert W. Gore tarafından keşfedilmiştir. ePTFE, karbon ve florin atomlarının birleşimiyle oluşmuştur (Şekil 2.23). En iyi kimyasal inert biyouyumlu polimerlerden biri olarak bilinmektedir. ePTFE, mikrogözenekli, düğüm ve fibril yapısından oluşmaktadır[4].

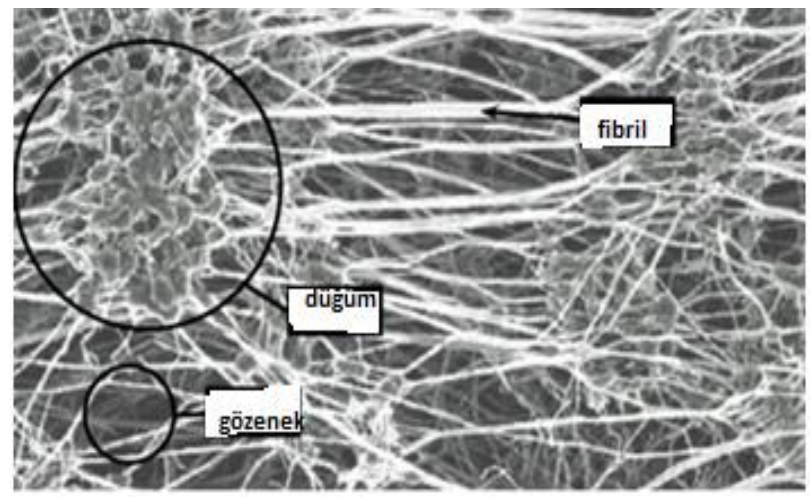

Şekil 1. ePTFE Grefte Yakından Bir Bakış (Gore, 2011).

ePTFE, mekanik dayanıklılığı, kimyasal durağanlığı ve yapıştırıcı olmaması nedeniyle, küçük ve orta ölçüdeki vasküler greftler için yaygın olarak kullanılan bir biyomateryaldir. ePTFE vasküler greftler, orta ölçüdeki damarlar için (iç çapı 6-8mm) kullanılmaktadır. Bununla birlikte, daha küçük çaplardakiler ( $5 \mathrm{~mm}$ 'den küçük) için greft verimi trombotik tıkama, tromboembolizm, intimal hiperplazi (hücrelerin anormal çoğalması) ve enfeksiyon gibi patolojik problemler ile sinırlanmaktadır[5-9].

Yapay malzemeler kullanılırken cerrahi sonrası bazı sorunlar yaşanabilmektedir. Yapay damarda da tıkanıklıklar olabilir, bakteri üreyebilir, delik veya yırtıklar oluşabilmektedir. Genelde yapay damarda oluşan sorunlar, tıkanıklıklardır. Bunun yanısıra biyouyumluluk, biyolojik açıdan malzemenin uyumlu olması da istenen bir özelliktir. Ayrıca malzeme cerrahi sonrası da oluşacak sorunlara karşı da enfeksiyon oluşturmamalıdır. Yapay malzeme üzerine farklı metal ve metal+gaz iyon implantasyonları yapılabilir. Böylece yapay doku yüzeylerine biyouyumluluk, süperhidrofobluk, enfeksiyonlara karşı antibakteriyel özellik kazandırılabilir. Pürüzlülük ve sürtünme azaltılıp istenmeyen durumlarda hücre tutunmasının önüne geçilebilir ve kanın pıhtılaşması önlenebilir. Ayrıca kalpteki delik ve yırtıklarda kullanılan yamaların yüzeyleri iyon implantasyonu ile modifiye edilebilmesi amaçlanmaktadır.

\subsection{Kardiyoloji Alanda İyon İmplantasyonun Uygu- lama Alanları}

Şekil 2.'de gösterilen MEVVA (metal buharlı vakum ark) İyon İmplantasyonu Sistemi, yüksek akımlı metal iyonlarının vakum ark ile üretilerek yoğun ve 
yüksek iyonizasyon derecesindeki metal plazmadan metal iyonların çekilip yüksek enerjilerde hızlandırılmalarını sağlamaktadır[10-12]. İyon implantasyon işlemi ABD'de FDA onaylıdır. İnsanların vücudunda ömürleri 10-15 yıldan 30-40 yıla çıkar. Yaşlı kişilerde de uygulanabilir. Çünkü vücutta komplikasyonlar oluşturmaz, dokuların enfeksiyon kapma riskleri azalır.

Yüzeyi iyon implantasyon işlemi gören kateterlerin kayganlığı artar, kanın pıhtılaşması önlenir (ticari olarak uygulanmaktadır) ve dokuların enfeksiyon kapma riskleri azalır. Yapay kalp kapakçıklarının da iyon implantasyon işlemi gördükten sonra ömürleri artmakta ve kan pıhtılaşması önlenmektedir. Böylece hastalarda komplikasyonlar önlenmektedir.

Kalp ve damar cerrahisinde kullanılan politetrafloroetilen (PTFE) yapay malzemede oluşan sorunların giderilmesi amacıyla bazı araştırmacılar bu malzemelere iyon implantasyonu uygulamaları yapmışlardır[13]. Amaç bu uygulamalarla malzemeye yeni özellikler kazandırmaya çalışmaktır.

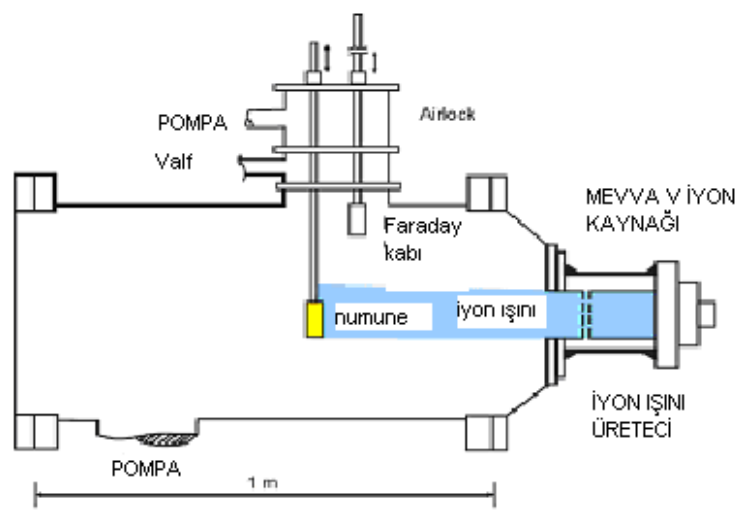

Şekil 2. MEVVA İyon İmplantasyon Sistemi[11]

Japonya'da yapılan bir çalışmada, damarlarda meydana gelen deliklerin kapatılarak kanama, yüzeyi $\mathrm{Ar}$ veya metal iyonlarla ışınlanmış PTFE filmlerle durdurulabilmektedir[14]. Ayrıca köpek üretrasında kullanilabilecek bir protez olarak ringli PTFE tüp greft ile ilgili deneysel bir çalışma yapılmıştır[15]. Birçok çalışmada PTFE'nin iyon implantasyonuyla sağladığ yararlar görülmektedir.

Kardiyovasküler cerrahide kullanılan yapay PTFE malzemelere iyon implantasyonu çalışmasıyla tıpta kalp ve damar cerrahisinde sıklıkla kullanılan yapay malzemelere iyon implantasyonu tekniği ile istenilen özellikler kazandırılmıştır[16]. Almanya'daki Fraunfoher Enstitüsü, 3 boyutlu yazıcıları ve lazer teknolojisini kullanarak yapay damar üretmiştir[17]. Ameliyat sonrası oluşabilecek sorunları azaltmak veya ortadan kaldırmak için yapılan bu çalışma, insan sağlığına olumlu katkılar sağlamayı amaçlamaktadır.

Ar ve metal iyonlarla implante edilmiş ePTFE malzemelerle N. Takahashi ve arkadaşlarının yaptığı bir çalışmada, damarlarda meydana gelen deliklerin kapatılarak kanamanın durdurabildiği gösterilmiştir. Cerrahide, küçük hasarlı damarlardan kanama, genellikle tıkanma olmadan hemostasia (kan toplanması) olduğunda hemen oluşmaktadır. Damarlarda küçük delikleri onarmak için $0.06 \mathrm{~mm}$ kalınlığında iyonlar ile implante edilmiş ePTFE filmler kullanılmıştır. ePTFE filmlerin her iki yüzeyi de $5 \times 10^{14}$ iyon/ $\mathrm{cm}^{2}$ akım ile $150 \mathrm{keV}$ enerjide Ar iyonu ile implante edilmiştir. Tavşanın şah damarına benzer $2 \mathrm{~mm}$ çapında küçük bir delik oluşturulmuştur. Bozukluk, iyon ışınlanmış veya işınlanmamış ePTFE malzemelerle sarılmaktadır. Fibrin yapıştırıcı ile şah damarına benzer ePTFE malzemeler kanama olan bölgeye yapıştırılmıştır. İmplantasyondan 3 hafta sonra, hiç tıkanma gözlenmemektedir. Histolojik inceleme, damar yollarının yenilenmesi için ePTFE'nin bir yapı iskelesi olarak işlev yaptığını göstermektedir. İyon ile implante edilmiş ePTFE malzemler vasküler cerrahide yararlı olacağı düşünülmektedir[14].

Y. Suzuki ve arkadaşlarının yaptığ çalışmada amaç, iyon 1şını teknolojisini kullanarak antitrombojenik koroner stent ve greft materyalleri geliştirmektir. Bu çalışmanın sonuçlarından $\mathrm{He}^{+}$işınlanmış kollajenin antitrombojenitesine, fibrinojen veya von Willebrand faktörü iyon demeti ışınlama ve plazma protein adsorbiyonunun (soğurma) azalması neden olmuştur. Bu hayvan çalışmasında $3-4,5 \mathrm{~kg}$ ağırlığındaki beyaz Japon tavşanı kullanılmıştır. Şekil 3.'de gösterildiği gibi $1 \times 10^{14}$ iyon $/ \mathrm{cm}^{2}$ dozunda $\mathrm{He}^{+}$iyonu ile implante edilmiş kollajen kaplamalı greft materyali mükemmel bir antitrombojenite olmuş ve 1 yil boyunca açılık göstermiştir[18]. 

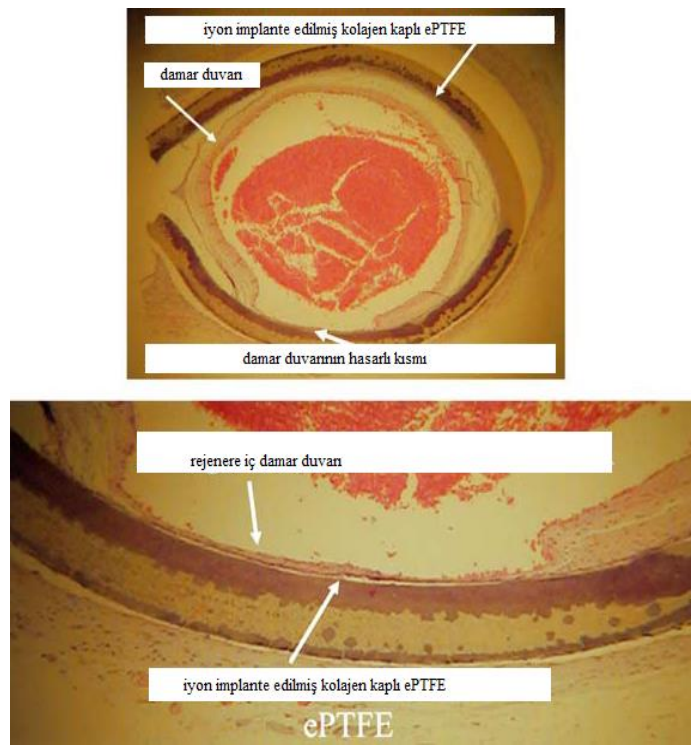

Şekil 3. He İyon İmplante Edilmiş PTFE Yüzey ile Örtülmüş, Tavşan Hasarlı Karotid Damarının İmplantasyondan 90. Gün Görünümü[18]

Kore'de Sung R. Kim, PTFE'nin yüzey modifikasyonu üzerine bir çalışma yapmıştır. İşlem öncesi ve sonrası CAM FILM temas açısı ölçüm cihazı ile PTFE' nin 1slaklığı ölçülmüştür. Yüzey ile temas açısı ölçülmesi, polimer yüzey enerjisinin hızlı ve nitelikli bir şekilde değerlendirmesine imkan verir. İşlem görmeyen PTFE'nin temas açısı $105^{\circ}$ ve bu çok özel polimerik materyaller arasında PTFE'nin en yüksek temas açısıdır yani PTFE'nin çok düşük yüzey enerjisine sahip olduğunu göstermektedir. Ar ve $\mathrm{O}$ işınlamasında PTFE'nin temas açısı artmaktadır. İyon 1şınlanmış PTFE numunelerin temas açısı, $1 \times 10^{17}$ iyon dozunda $140^{\circ}$ den fazladır ve su damlacığı, PTFE yüzeyinde meyilli bilye halindedir[19].

Bu çalışmada, sentetik damarların yapıldığı ePTFE malzemesine yeni özellikler kazandırmak amacıyla (antibakteriyel ve süperhidrofob özellikler) metal+gaz (hibrid) iyon implantasyonu yapılmıştır. ePTFE, Dacron'a göre daha inert özelliğe sahiptir. Toksik değillerdir, çabuk yıpranmazlar. İmplante edilen en yaygın malzemelerden biridir.

\section{Materyal ve Metod}

\subsection{Materyal}

Bu çalışmada, Ege Üniversitesi Kalp ve Damar Cerrahisi'nden temin edilen ePTFE malzemeler 66 adet $1 \mathrm{~cm} \times 1 \mathrm{~cm}$ ve 3 adet $2 \mathrm{~cm} \times 2 \mathrm{~cm}$ ebatında kuponlar halinde kesilerek iyon implantasyonunda kullanılmıştır. Numunelere, Ege Üniversitesi Yüzey Modifikasyon Laboratuarı'ndaki MEVVA İyon İmplantasyonu Sistemi ile (Şekil 4.) gümüş (Ag) iyon implantasyonu yapılmıştır. Tablo 1.'de iyon implantasyon parametreleri verilmiştir.

Tablo 1. İyon İmplantasyon Parametreleri

\begin{tabular}{|c|c|c|c|c|c|}
\hline Numune & $\begin{array}{c}\text { Numune boyutları } \\
(\mathrm{cm})\end{array}$ & İyon & $\begin{array}{c}\text { Doz } \\
\left(\mathrm{iyon} / \mathrm{cm}^{2}\right)\end{array}$ & $\begin{array}{c}\text { Hizlandırıc voltaj1 } \\
(\mathrm{kV})\end{array}$ & $\begin{array}{c}\text { Darbe Sayıs } \\
\left(\mathrm{Sn}^{-1}\right)\end{array}$ \\
\hline $\begin{array}{c}\text { ePTFE yapay } \\
\text { malzeme }\end{array}$ & $\begin{array}{c}\text { Boy: } 1 \\
\text { Uzunluk: } 1\end{array}$ & $\mathrm{Ag}$ & $1 \times 10^{14-15-16}$ & 20 & 2 \\
\hline
\end{tabular}

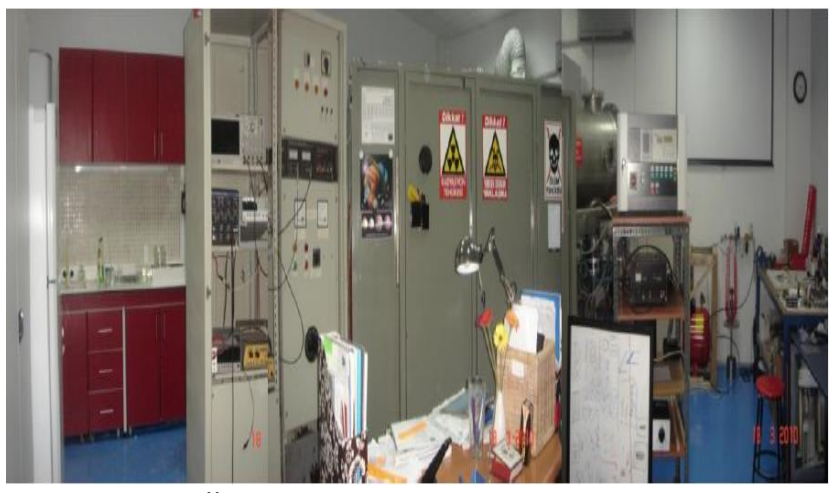

Şekil 4. Ege Üniversitesi Mühendislik Fakültesi Yüzey Modifikasyon Laboratuvarındaki MEVVA İyon İmplantasyon Sistemi Genel Görünümü,

\subsection{Metod}

\section{Antibakteriyel test:}

$\mathrm{Bu}$ çalışmada iyon implantasyonu uygulanan yapay malzemelere Staphylococcus Aureus bakterileri ekilerek AATCC 100-1999 standardına göre antibakteriyel olup olmadıklarına bakılmıştır. Yaptığımız antibakteriyel testte bakteri ekimi yapılacak olan ve deney sırasında kullanılacak diğer malzemelerin sterilizasyonu için, basınçlı buhar sterilizasyon yönteminden faydalanılmış ve doymuş su buharı ile çalışan Nüve OT 4060 marka otoklav kullanılarak 3 atm basınç altında $121^{\circ} \mathrm{C}$ sıcaklıkta 1 saat süre ile sterilizasyon işlemi yapılmıştır. 
Antibakteriyel etkinlik değerlendirilmeleri, AATCC 100-1999 test yöntemi kullanılarak yapılmıştır. Bu test yöntemi, antibakteriyel etkinlik derecesini kantitatif olarak belirleyen bir prosedürdür. Antibakteriyel etkinlik değerlendirilmesinde, gram-pozitif bakteri suşu olarak S. aureus (ATCC 6538) seçilmiştir. Bu yönteme göre, $38 \mathrm{~mm}$ çapında kesilen 4 adet test ve kontrol kumaş örnekleri, $3 \mathrm{~atm}$ basınç altında $121^{\circ} \mathrm{C}$ sıcaklıkta 1 saat süre ile sterilize edildikten sonra örneklere 1,0 $\pm 0,1 \mathrm{~mL}^{\prime}$ lik bakteri (1 Mcfarland standart yoğunlukta; $1,5-3 \times 10^{8}$ bakteri koloni oluşum birimi (CFU)) kültür çözeltisi aktarılır, 100 $\pm 1 \mathrm{~mL}^{\prime}$ lik steril distile su eklenir, sert bir biçimde çalkalanır ve "0 temas süresi" için distile su ile seri sulandırmalar yapılarak Muller-Hinton II agar besiyerine ekimler yapılır. Örnekler, $37^{\circ} \mathrm{C}^{\prime}$ de 24 saat inkübe edildikten sonra "24 saat temas süresi" için distile su ile seri sulandırmalar yapılarak Muller-Hinton II agar besiyerine ekimler yapılır. İnkübasyondan sonra, agar plakaları üzerindeki bakteri kolonileri sayılır ve bakteri sayısındaki \% azalma aşağıdaki eşitlik kullanılarak hesaplanir.

Bakteri azalma oranı $(\%)=[($ A - B $) / A] \times 100$

A : 24 saat süresince inkübe kavanozdaki inoküle işlem görmüş test örneklerinden geriye kalan bakteri sayıs.

B : İnokülasyondan sonra ("0" temas zamanında) kavanozda hemen inoküle işlem görmüş test örneklerinden geriye kalan bakteri sayısı.

Hesaplanan \% miktar, ne kadar yüksek ise, antibakteriyel etkinlik o kadar yüksektir.

\section{Atomik kuvvet mikroskobu (AFM):}

PTFE yüzeyin 1slatma özelliklerinde mikro pürüzlülüğünün etkisi, yüzey pürüzlülüğünü karakterize etmek için AFM kullanılarak incelenmiştir. Yüzey pürüzlülüğü iki farklı yüzey için bakılıp ortalama pürüzlülüğü hesaplanmıştır. İşlem sonrası yüzey pürüzlülüğünün azaldığı görülmüştür(Miller,1996). Bu çalışmada, numuneler Ag iyon implantasyonundan sonra yüzey pürüzlülüğünün değişip değişmediğini incelemek için İzmir Yüksek Teknoloji Enstitüsü Fizik Bölümü'ndeki NT-MDT Molecular Devices and Tools for Nanotechnology, SOLVER Scanning Probe Microscope cihazı ile yapılmıştır.

Temas açısı:

$\mathrm{Bu}$ çalışma için temas açısı ölçümleri Ege Üniversite- si Tekstil ve Konfeksiyon Araştırma-Uygulama Merkezi'ndeki KSV Instrument firmasının CAM101 modeli cihazında yapılmıştır. Bu cihaz 2007-K120780 nolu DPT Tekstil ve Deri Sanayi Doktora Programinda alınmıştır.

\section{Bulgular}

Tablo 2.'de farklı doz ve aynı enerjideki Ag implante edilmiş ePTFE numunelerinde S.aureus bakterileri için AATCC 100-1999 test yöntemi kullanılarak yapılan değerlendirme sonuçları verilmiştir. S. aureus bakterisi ile yapılan testlerde Ag implante edilmiş ePTFE yapay numunede \% 100 e yakın bakteri azalması elde edilmiştir.

Tablo 2. S.Aureus Bakterisi ile Yapılan Antibakteriyel Test Sonuçları

\begin{tabular}{|c|c|}
\hline $\begin{array}{c}\text { Numune } \\
\text { Toplam bakteri } \\
\text { (cfu/numune) } \\
239.875 .000\end{array}$ & $\begin{array}{c}\text { Bakteriyel Azalma } \\
\text { Oranı \% }\end{array}$ \\
\hline $\begin{array}{c}\text { Ag } 10^{14} \text { iyon } / \mathrm{cm}^{2} 20 \mathrm{kV} \\
\text { (implante) }\end{array}$ & 93,95 \\
\hline $\begin{array}{l}\mathrm{Ag} 10^{15} \text { iyon/cm² } \\
20 \mathrm{kV} \text { (implante) }\end{array}$ & 97,74 \\
\hline $\begin{array}{l}\mathrm{Ag} 10^{16} \text { iyon/cm² } \\
20 \mathrm{kV} \text { (implante) }\end{array}$ & 90,74 \\
\hline
\end{tabular}

Tablo 3.'de implante olmamış ve implante olmamış numunelerin temas açısı ölçüm sonuçları verilmiştir. Sonuçlara göre gümüş iyon implante edilmiş yüzeylerde implantasyon edilmemiş numunelerin temas açılarına göre bir artış gözlenmiştir.

Tablo 3. Temas Açısı Ölçüm Sonuçları

\begin{tabular}{|c|c|c|}
\hline & $\begin{array}{l}\text { 3. sn deki } \\
\text { temas açısı }\end{array}$ & $\begin{array}{l}\text { 57. sn deki } \\
\text { temas açıs }\end{array}$ \\
\hline $\begin{array}{l}\text { İmplante edilmemiş } \\
\text { ePTFE yapay numune }\end{array}$ & $100,3^{0}$ & $100,3^{0}$ \\
\hline $\begin{array}{l}\mathrm{Ag} 10^{14} \text { iyon } / \mathrm{cm}^{2} \\
20 \mathrm{kV} \text { (implante) }\end{array}$ & $102,1^{0}$ & $101,6^{0}$ \\
\hline $\begin{array}{l}\mathrm{Ag} 10^{15} \text { iyon } / \mathrm{cm}^{2} \\
20 \mathrm{kV} \text { (implante) }\end{array}$ & $131,4^{0}$ & $131,6^{0}$ \\
\hline $\begin{array}{l}\mathrm{Ag} 10^{16} \text { iyon } / \mathrm{cm}^{2} \\
20 \mathrm{kV} \text { (implante) }\end{array}$ & $95,46^{0}$ & $94,82^{0}$ \\
\hline
\end{tabular}

Yapılan incelemede implante edilmemiş numunele- 
rin, Ag ve $\mathrm{Zn}+\mathrm{O}$ hibrid implante edilmiş numunelerin yüzeylerinin pürüzlülükleri incelenmektedir. İncelemelerde farklı alanlarda taramalar yapılmıştır. Şekil 5. ve Tablo 4.'de yeralan görüntülerde ve verilerde yüzey pürüzlülük analiz sonuçları verilmiştir.

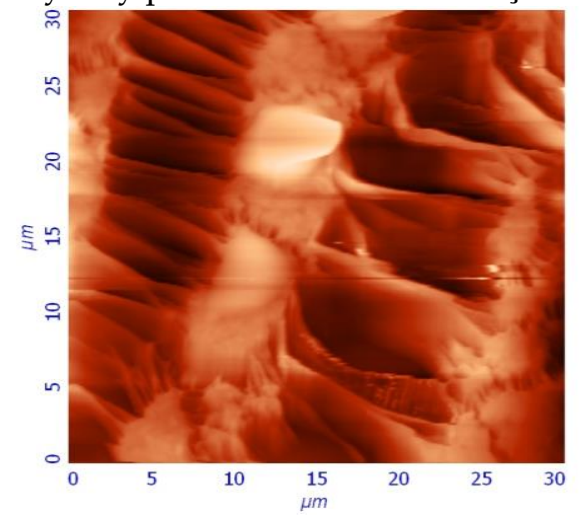

a.

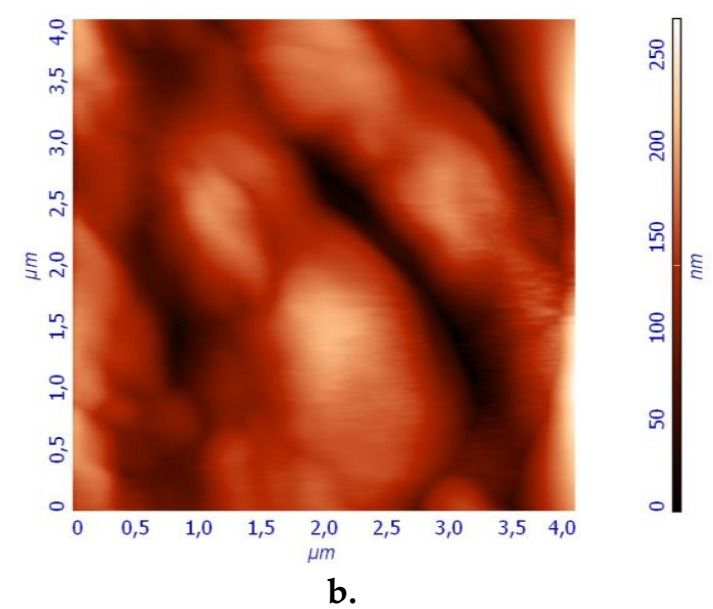

Şekil 5. (a.) İmplante Edilmemiş Numunenin AFM Görüntüsü. (b.) Ag İmplante Edilmiş Numunenin AFM Görüntüsü.

Tablo 4. Kontrol ve Ag İmplante Edilmiş Numunelerin AFM Yüzey Pürüzlülük Analizi Sonuçları

\begin{tabular}{|l|l|}
\hline $\begin{array}{l}\text { İmplante olma- } \\
\text { miş(kontrol) numune için } \\
\text { ort. pürüzlülük değeri }\end{array}$ & $\begin{array}{l}\text { Ag implante edilmiş } \\
\text { numune için ort. } \\
\text { pürüzlülük değeri }\end{array}$ \\
\hline $280,03 \mathrm{~nm}$ & $58,12 \mathrm{~nm}$ \\
\hline
\end{tabular}

\section{Tartışma:}

Kardiyovasküler cerrahide kullanılan yapay genişletilmiş politetrafloroetilen (ePTFE) malzemelere Ag iyon implantasyonu yapılarak yeni özellikler kazandırmak amacıyla yapılan bu çalışmada 35 adet yapay
ePTFE numunenin farklı dozlarda fakat aynı enerjideki iyonların implantasyonu yapılmıştır. İyon dozları 1x1014-15-16 iyon/ $/ \mathrm{cm}^{2}$, hizlandırıcı voltajları $20 \mathrm{kV}$ olarak belirlenmiştir.

Yapay numunenin bakteri üretip üretmediğini kontrol etmek için yaptığımız antibakteriyel testte kullanulan S. Aureus bakterisi, Staphylococcaceae ailesinden bir bakteridir. Yaklaşık 20 türü vardır. İnsan cilt florasında kommensal olarak da bulunur. Mikroskobik olarak incelendiğinde çift, kısa zincirli ve üzüm gibi salkım halinde olduğu gözlenen, kok (küresel) şekilde, Gram pozitif bir bakteridir[20]. Antibakteriyel etkinlik açısından hesaplanan \% miktar, ne kadar yüksek ise, antibakteriyel etkinlik o kadar yüksektir. Yaptığımız testlerde genel olarak bakteri çoğalmasının olmadığı saptanmıştır. \%97,7 değerinde bakteri azaldı̆̆ı görülmüştür.

Gümüş, çinko, bakır, civa, titanyum gibi ağır metaller antibakteriyel aktiviteye sahiptirler[21]. Literatürde varolan bilgiler işığında, bu çalışmadaki antibakteriyel etkinliğin artışı, Ag iyon implantasyonuyla ilişkilendirilmektedir. Bu metal iyonları bakteri enzimlerini etkisiz hale getirerek bakterilerin enzim reaksiyonlarını gerçekles,tirmesini olanaksızlas,tırırlar[22, 23]. Bunların içinden iyonik haldeki gümüs, maddelere en yuiksek antibakteriyel aktiviteyi saglar[22, 24, 25]. Gümüşün bu özelligì ve zehirli olmaması, Ag iyon implantasyonunun kullanım alanlarını genişletmektedir[26].

Bu çalışmadaki temas açıları incelendiğinde, implante olmayan yapay ePFTE numunesinin temas açısı $100,3^{0}$ olarak saptanmıştır. Yani ePTFE numunesinin hidrofob özellikte olduğunu göstermektedir. Çalışmada amaçladığımız superhidrofob hale getirme özelliğini kazandırmak için, Ag implantasyonu üç iyon dozunda ve sabit voltajda yapılmıştır. En iyi sonucu $1 \times 10^{15} \mathrm{iyon} / \mathrm{cm}^{2}$ iyon dozunda elde edilmiştir. Temas açısı 131, $6^{0}$ olup süper hidrofobluğa uygun bir değer sağlanmıştır. Açının çok fazla düşmemesi yapılan çalışmanın iyi sonuç verdiğini göstermektedir. Ayrıca kaplamanın temas açısını çok fazla etkilemediği anlaşılmaktadır. Süperhidrofob olması cerrahide kullanımını daha elverişli hale getirmektedir.

Temas açısını etkileyen en önemli faktörler, yüzey 
enerjisi ve pürüzlülügüüür. Yüzey enerjisi düşük olan yüzeylerin pürüzlendirilmesi veya pürüzlü yüzeylerin enerjisi düşük olan madde ile kaplanması sağlanılabilmektedir. Yüzey gerilim düştükçe değme açısı da düşer. Pürüzlülük yüzeyle su damlası arasında hava sıkışmadığı için aradaki etkileşme miktarını da düşürür[15].

Kore'den Sung R. Kim'in, PTFE ile yaptığı çalışmasında işlem görmemiş PTFE'nin temas açısı $105^{\circ}$ dir yani PTFE'nin çok düşük yüzey enerjisine sahip olduğunu göstermektedir[19]. Bu çalışmada Ar ve O 1şınlamasında PTFE'nin temas açısı artmaktadır. İyon 1şınlanmış PTFE numunelerin temas açısı, $1 \times 10^{17}$ iyon dozunda $140^{\prime}$ den fazladır ve sonuçlar bizim elde ettiğimiz sonuçlarla uyumludur

AFM ile yapılan analizlerde yüzey pürüzlülük ölçümleri, implante olmamış ve Ag implante olmuş numunelerin farklı alanları taranarak yapılmıştır (20 $\mu \mathrm{m} \times 20 \mu \mathrm{m}, 30 \mu \mathrm{m} \times 30 \mu \mathrm{m}, 40 \mu \mathrm{m} \times 40 \mu \mathrm{m})$. İmplante olmamış numunelerin ortalama pürüzlülük değeri 280,033 nm'e kadar ulaşmıştır. Ag implante edilmiş numunelerin ortalama pürüzlülük değeri 58,12nm'e kadar düşmüştür. Sonuç olarak implantasyon ile pürüzlülüğün azaldığı görülmüştür.

Daha önce yapılan çalışmalarda Genel olarak temas açısı azaldıkça yüzey geriliminin azaldığ görulmüștür [20]. Değme açısını etkileyen en önemli faktörler katının yüzey enerjisi ve pürüzlülüğüdür. Yüzey enerjisi, yüzey gerilimi sonucu ortaya çıar. Yüzey pürüzlülügünün artması ise hem hidrofilik hem hidrofobik özelliklerin artmasina neden olur. Pürüzlülük yüzeyle su damlası arasında hava sıkışmasını sağladığı için aradaki etkileşme miktarını da düşürür, dolayısıyla temas açısı hidrofobik yüzeylerde artar. Bizim çalışmamızda pürüzlülüğün azalması ile yüzeyin hidrofobik özellik sergilemesi bu bilgilerle uyumludur[21].

\section{Sonuç}

Yapılan çalışmalarda iyon implantasyonunun yumuşak yapıya sahip yapay ePTFE numunesinin yüzeyine zarar vermediği görülmektedir. Antibakteriyel testlerde ve temas açılarının ölçümlerinde hızlandırı$\mathrm{cl}$ enerji $20 \mathrm{kV}$, iyon dozunun ise $1 \times 10^{15} \mathrm{iyon} / \mathrm{cm}^{2} \mathrm{ol}-$ duğu durumlarda genellikle iyi sonuçlar elde edil- miştir. $1 \times 10^{15}$ iyon/ $/ \mathrm{cm}^{2}$ dozda ve $20 \mathrm{kV}$ hızlandırma voltajı altında elde edilen sonuçlara göre Ag İyon implantasyonu olmuş PTFE numunelerin optimum temas açısı 131, $6^{0}$ olarak belirlenmiştir. $\mathrm{Bu}$ doz ve enerji değerinde antibakteriyel etkinlikte \%97,7 azalma ölçülmüştür ve pürüzlülük test sonuçlarına göre ortalama pürüzlülük değeri 58,12 nm'dir.

\section{Referanslar}

[1] Hasson, J.; Abbott, W. Complications of arterygraft compliance mismatch. Complications in vascular surgery. 1985; 545.

[2] Eren, S.; Ulcay, Y. Yapay Tekstil Damarları. Tekstil Teknolojileri Elektronik Dergisi. 2010; 4, 35-47.

[3] Atay, Y. Kalp Damar Cerrahisi ve Nanoteknoloji. Nanotechnology in Medicine Sempozyumu. Ege Üniversitesi Tıp Fakültesi 2011.

[4] Gore. Erişim tarihi, 25 Ağustos 2011, http://www.goremedical.com, 2011.

[5] Hanson, S. R. Chapter 15 Device thrombosis and thromboembolism. Cardiovascular Pathology.1982; 2, 157-65.

[6] Abbot, W.; Cambria, R.; Stanley, J. Biological and synthetic vascular prosthesis. New York: Grune and Stratton. 1982.

[7] Bronzino, J. D. Biomedical engineering handbook: CRC press, 1999.

[8] Brewster, D. Vascular Surgery. Philadelphia, PA: Saunders, 2000.

[9] Höcker, D. K. H. Polymers for Biomedical Applications: Improvement of the Interface Compatibility. Advances in Polymer Science: Springer; 2000; 1-57.

[10] Brown, I. G. The physics and technology of ion sources: John Wiley \& Sons, 2004.

[11] Öztarhan A. Gaz ve Metal İyon İmplantasyon Tekniği ile Malzeme Yüzeylerinin Modifikasyonu ve Yeni Malzemelerin Oluşturulması. TUBİTAK; 2005. 
[12] Urkac, E.S.; Oztarhan, A.; Tihminlioglu, F.; Kaya, N.; Ila, D.; Muntele, C. et al. Thermal characterization of $\mathrm{Ag}$ and $\mathrm{Ag}+\mathrm{N}$ ion implanted ultra-high molecular weight polyethylene (UHMWPE). Nuclear Instruments and Methods in Physics Research Section B: Beam Interactions with Materials and Atoms. 2007; 261, 699-703.

[13] Zhang, J.; Zhang, X.; Zhou, H.; Effect of aging on surface chemical bonds of PTFE irradiated by low energy Ti ion. Applied Surface Science. 2003; 205, 343-52.

[14] Takahashi, N.; Suzuki, Y.; Ujiie, H.; Hori, T.; Iwaki, M.; Yamada, T. Application of ion beam irradiated ePTFE to repair small vessel injuries. Nuclear Instruments and Methods in Physics Research Section B: Beam Interactions with Materials and Atoms. 2007; 257, 114-7.

[15] Verit, A.; Darçın, O.; Yeni, E.; Ünal, D.; Özardalı, İ.; Karataş, Ö. Graft Nrpt. Köpek Üretrasinda Kullanilabilecek Bir Protez Olarak Ringli Politetrafluoroetilen Tüp Greft: Deneysel Önçalişma. Türk Üroloji Dergisi. 2003; 29 (3) , 241-244.

[16] Fedakar, A.; Mataracl, İ.; Şaşmazel, A.; Büyükbayrak, F.; Aksüt, M.; Eren, E. et al. Abdominal aort anevrizmasinda elektif ve acil cerrahi onarım. Turkish Journal of Thoracal Cardiovascular Surgery. 2010; 18, 100-5.

[17] Özgür, H.; Gemici, Z.; Bayındır, M. Akıllı Nanoyüzeyler. Bilim Teknik Dergisi. 2007; 52-56.

[18] Suzuki, Y.; Iwaki, M.; Takahashi, N.; Yotoriyama, T.; Kurotobi, K.;, Ujiie, H. et al. In vitro and in vivo study of $\mathrm{He}+$ ion irradiated collagen for development of small diameter stent graft material. Nuclear Instruments and Methods in Physics Research Section B: Beam Interactions with Materials and
Atoms. 2005; 232, 353-7.

[19]Kim, S. R. Surface modification of poly (tetrafluoroethylene) film by chemical etching, plasma, and ion beam treatments. Journal of Applied Polymer Science. 2000; 77, 1913-20.

[20] Kut, D.; Güneşoğlu, C. Nanoteknoloji ve tekstil sektöründeki uygulamaları. Tekstil\&Teknik Dergisi, İstanbul. 2005; 224-30.

[21] Balcı, H. Akıllı (fonksiyonel) tekstiller, seçilmiş kumaşlarda antibakteriyel apre ve performans özellikleri. Yüksek Lisans Tezi, Çukurova Üniv, Adana 2006; 25-45.

[22] Rivera-Garza, M.; Olguín, M.T.; García-Sosa, I.; Alcántara, D.; Rodríguez-Fuentes, G. Silver supported on natural Mexican zeolite as an antibacterial material. Microporous and Mesoporous Materials. 2000; 39, 431-44.

[23] Kokkoris, M.; Trapalis, C.; Kossionides, S.; Vlastou, R.; Nsouli, B.; Grötzschel, R. et al. RBS and HIRBS studies of nanostructured AgSiO 2 sol-gel thin coatings. Nuclear Instruments and Methods in Physics Research Section B: Beam Interactions with Materials and Atoms. 2002; 188, 67-72.

[24] Klasen, H. A historical review of the use of silver in the treatment of burns. II. Renewed interest for silver. Burns. 2000; 26, 131-8.

[25] Top, A.; Ülkü, S. Silver, zinc, and copper exchange in a Na-clinoptilolite and resulting effect on antibacterial activity. Applied Clay Science. 2004; 27, 13-9.

[26] Kawashita, M.; Toda, S.; Kim, H-M.; Kokubo, T.; Masuda, N. Preparation of antibacterial silver-doped silica glass microspheres. Journal of Biomedical Materials Research Part A. 2003; 66A, 266-74. 